\title{
Performance of village fowl in Malaysia
}

\begin{abstract}
Throughout south-east Asia the keeping of indigenous domestic fowl by village communities has been practised for many generations. The custom is likely to continue and remain popular in rural areas. This paper reviews the performance of these fowl in respect of body weight and egg production under intensive and semi-intensive husbandry systems in Malaysia.
\end{abstract}

Keyword: Chicken; Domestic fowl; Egg production; Growth; Malaysia; System; Village 